\title{
Reflexões sobre as relações entre design, design de produção audiovisual e narrativa transmídia
}

\author{
Reflections about the relationships between design, audiovisual \\ production design, and transmedia storytelling
}

KURZ, Lucas

Universidade Federal do Maranhão - UFMA I lucasmkurz@gmail.com

OBREGON, Rosane

Universidade Federal do Maranhão - UFMA I antunesobregon@gmail.com

ZANDOMENEGHI, Ana Lucia Alexandre de Oliveira

Universidade Federal do Maranhão - UFMA I ana.zandomeneghi@ufma.br

DINIZ, Raimundo Lopes

Universidade Federal do Maranhão - UFMA I rl.diniz@ufma.br

\begin{abstract}
Resumo
Este artigo discorre acerca das relações entre design, Design de Produção Audiovisual e narrativa transmídia. Partindo dos diferentes parâmetros teóricos envolvendo o design, visa caracterizar e articular possíveis relações entre esses temas. Para isso, são abordados conceitos sobre a natureza transdisciplinar e complexa do design, e as definições e particularidades dos conceitos de Design de Produção Audiovisual e narrativa transmídia. Finalmente, com reflexões sobre esses temas, buscam-se considerações sobre as relações existentes entre eles. O trabalho propõe, então, situar o processo criativo na teoria do design e, a partir disso, no Design de Produção Audiovisual e na narrativa transmídia, buscando evidenciar a essência comum que integra os temas no campo do design.
\end{abstract}

Palavras-chave: Teoria do design. Narrativa transmídia. Design de produção audiovisual. Narrativa visual.

\section{Abstract}

This paper addresses the relationship between design, audiovisual production design and transmedia storytelling. Starting from multiple theoretical backgrounds involving design, we aim to explain, understand, and build possible connections between the subjects. To this end, we discuss the cross-curricular teaching and the complex nature of design, we well as the definitions of production design and transmedia storytelling. Finally, we propose reflections on the relationships between the topics. This study intends to improve the comprehension on production design and transmedia storytelling, which includes the understanding of the creative process in design, in order to establish common grounds between these subjects and the design universe.

Keywords: Design theory. Transmedia storytelling. Production design. Visual narrative. 


\section{INTRODUC̣ÃO}

O design, enquanto corpo de conhecimento e área de atuação, está em constante conceituação e, por ser um conceito complexo, possui variadas atribuições e subáreas. Entre as principais características do design está sua natureza transdisciplinar, a possibilidade de cooperar com outras disciplinas em um conjunto coerente e unificado.

Da intersecção entre o design e o audiovisual surge a prática do Design de Produção Audiovisual - de acordo com Vincent LoBrutto (2002), a arte e ofício visual da narrativa audiovisual - na qual o pensamento projetual do design aplica-se à abordagem visual da narrativa. $O$ designer de produção audiovisual herda do campo do design a natureza multifacetada, trabalhando com uma equipe transdisciplinar na criação de um universo visualmente íntegro.

Se estabelece, então, uma interface entre a área do design, o Design de Produção enquanto prática projetual e a narrativa transmídia, conceito cunhado por Henry Jenkins (2009) que se refere a uma narrativa que se desenvolve através de múltiplos suportes midiáticos.

Assim, este trabalho consiste em uma discussão teórica de caráter exploratório, o qual articula uma breve reflexão crítica acerca da inter, multi e transdisciplinaridade no design, do Design de Produção Audiovisual e da narrativa transmídia, para então pensar de que forma esses três conceitos podem ser relacionados sob o viés do design. É, portanto, uma pesquisa de abordagem qualitativa, uma vez que preocupa-se "com aspectos da realidade que não podem ser quantificados, centrando-se na compreensão e explicação da dinâmica das relações sociais" (GERHARDT; SILVEIRA, 2009, p. 32). Quanto aos objetivos, é uma pesquisa exploratória, pois "tem como objetivo proporcionar maior familiaridade com o problema, com vistas a torna-lo mais explícito" (GERHARDT; SILVEIRA, 2009, p. 35).

\section{INTER, MULTI E TRANSDISCIPLINARIDADE NO DESIGN}

Possatti, Van Der Linden e Silva (2015) evidencia que 'design' possui caráter polissêmico, que possui diversidade de definições e descrições, e pode ser entendida de variadas formas: enquanto verbo, substantivo abstrato, representação, artefato, resolução de problemas, aparência de um produto, atividade profissional, disciplina e pesquisa.

Em decorrência disso, defende que a palavra remete à complexidade de significados e, portanto, pode ser associada ao conceito de complexidade, que consiste em "um sistema composto de muitos elementos, camadas e estruturas, 
cujas inter-relações condicionam e redefinem continuamente o funcionamento do todo" (CARDOSO, 2012, p. 25).

Além disso, a autora defende que o design possui estreita associação com o conceito do pensamento complexo, postulado por Morin (2011), que define complexidade como a relação dialógica entre ideias paradoxais (ordem $\mathrm{x}$ desordem; uno x múltiplo, etc.), em que duas lógicas adversas necessitam uma da outra; integrando termos complementares, mas contrários.

Assim sendo, entende-se que o design é um conceito complexo, composto de muitos elementos, camadas e estruturas. A palavra 'design' é polissêmica, pode se referir a vários sentidos distintos, sendo isso reflexo do caráter complexo de entender seu significado. Além disso, é uma relação dialógica entre ideias paradoxais, está entre o abstrato e o concreto, entre a arte e a técnica, e esses aspectos adversos integram termos complementares, apesar de ambíguos.

Assim, ao se inter-relacionarem, essas estruturas condicionam e redefinem continuamente o funcionamento do todo. "Essas inter-relações podem não se restringir apenas ao sistema físico e ao seu funcionamento e de suas partes, mas também ao profissional do Design, o designer, e sua rede de relações com outros profissionais" (POSSATTI; VAN DER LINDEN; SILVA, 2015, p. 9).

Logo, considerando a ideia de Cardoso (2012) de que a complexidade faz parte do mundo e, portanto, é preciso aceitá-la, e a natureza do design, temse que "no mundo complexo em que vivemos, as melhores soluções costumam vir do trabalho em equipes e em rede" (CARDOSO, 2012, p. 23).

A natureza complexa do design reside também no âmbito da metodologia projetual, ligada "[...] ao número de componentes do problema, sejam peças ou disciplinas envolvidas" (VAN DER LINDEN; LACERDA, 2012, p. 88). Logo, compreende-se que a complexidade do design se manifesta também na variedade de suas subáreas, e da possibilidade de relacionar-se com outras profissões e disciplinas a fim de obter melhores soluções. Dessa forma, e de acordo com Morin (2007), complexidade é "aquilo que é tecido conjuntamente, aquilo que se deve enlaçar" (MORIN, 2007, p. 22).

Antonio Fontoura (2011) aponta que o design é por natureza interdisciplinar.

Há nele implícita uma vocação interdisciplinar, pois se trata de uma área propícia para o trabalho conjunto com outras áreas de conhecimento. Uma das características de 
uma atividade de Design é o envolvimento de inúmeros conhecimentos de domínios distintos. (FONTOURA, 2011, p. 92).

Ivani Fazenda (1979) conceitua a interdisciplinaridade como a

[...] interação existente entre duas ou mais disciplinas. Essa interação pode ir da simples comunicação de ideias à interação mútua dos conceitos diretores da epistemologia, da terminologia, da metodologia, dos dados de organização referentes ao ensino e à pesquisa. Um grupo interdisciplinar compõe-se de pessoas que receberam sua formação em diferentes domínios do conhecimento (disciplinas) com seus métodos, conceitos, dados e termos próprios. (FAZENDA, 1979, p. 27).

Assim, entende-se que a natureza do design permite a fusão com outros campos de conhecimento, contribuindo para o substrato teórico-prático para o avanço de pesquisas e produtos em outras áreas. Em razão da natureza complexa do design, permite-se múltiplas "subteorias".

Fertilizando e deixando fertilizar-se por outras áreas de conhecimento, o Design vem-se construindo e reconstruindo em um processo permanente de ampliação de seus limites, em função das exigências da época atual. Em linha com esta tendência, sua vocação interdisciplinar impede um fechamento em torno de conceitos, teorias e autores exclusivos. Sua natureza multifacetada exige interação, interlocução e parceria. (COUTO; OLIVEIRA, 1999, p. 7).

Isto posto, Bungarten e Nojima (2013) afirmam que, levando esses aspectos em consideração, vem-se buscando a essência do Design, no ímpeto de fundar uma teoria que o caracterize como ciência e área do conhecimento.

Todavia, devido às suas características abrangentes e flutuantes, entende-se que essa disciplina é por natureza instável, como corrobora Bomfim (1997, p. 29), “[...] é possível afirmar que uma Teoria do Design não terá campo fixo de conhecimentos, seja ele linear-vertical (disciplinar), ou linear-horizontal (interdisciplinar), isto é, uma Teoria do Design é instável". Assim, pode-se dizer que o design permite "uma redefinição constante do método de abordagem, dos seus possíveis objetos de estudo e do seu domínio científico" (BUNGARTEN; NOJIMA, 2013, p. 169).

Expandindo a reflexão, Morin apresenta as visões de multi e transdisciplinaridade. Segundo o autor, a 
Interdisciplinaridade é a associação das disciplinas umas às outras, cada uma conservando sua autonomia, tentando colaborar, mas com frequência entrando em conflito. [...] Mas o mais importante é a multidisciplinaridade, a união de diferentes disciplinas num conjunto coerente, que leva por si mesma à transdisciplinaridade (2007, p. 24).

Para compreender o ponto de vista do autor, é preciso esclarecer os conceitos apresentados. Para Zabala (2002), interdisciplinaridade refere-se ao reencontro e à cooperação entre uma ou mais disciplinas, tendo cada uma seus esquemas conceituais próprios, com significado personificado na palavra interação.

A multidisciplinaridade é a forma de intercâmbio em que a organização dos conteúdos das disciplinas ocorre independentemente umas das outras e seu significado pode ser compreendido pela palavra somativa.

Já a transdisciplinaridade é o contato e a cooperação entre disciplinas de forma que ambas acabam por adotar um mesmo conjunto de conceitos fundamentais, ou o mesmo paradigma, e é personificada na palavra unificação.

De acordo com Pereira Neto, Santos e Vandresen (2017), um designer, enquanto projetista de soluções necessárias à sociedade em forma de produtos ou sistemas, está inserido em um contexto no qual, sob a ótica da transdisciplinaridade, precisa transpor as barreiras das disciplinas para formular respostas competentes.

Ao designer, enquanto agente social que assiste, interage e por vezes determina o cenário em que está inserido, um pensamento transdisciplinar serviria como catalisador de atos criativos mais sofisticados. Novas maneiras de integrar as disciplinas também poderiam emergir de um pensamento criativo sistematizado. O designer é visto aqui como ator e por vezes autor de sua própria história. (PEREIRA NETO; SANTOS; VANDRESEN, 2017, p. 6).

Como apontam Bungarten e Nojima (2013), o design está em constante redefinição do seu método de abordagem, ou do seu domínio científico. Assim, e de acordo com Pereira Neto, Santos e Vandresen (2017), é possível e coerente pensar a unificação entre o design e outras disciplinas, sob o viés da transdisciplinaridade.

O design compõe um corpo teórico e área de atuação positivamente volúvel, e sua natureza multifacetada permite tanto a interação com outras disciplinas a nível de interdisciplinaridade, conservando sua autonomia, quanto 
a unificação com outras disciplinas, através da cooperação extrema, a união em um conjunto coerente que permite, segundo Pereira Neto, Santos e Vandresen (2017), formular respostas competentes e atos criativos mais sofisticados.

"O design desponta em um cenário [...] como saber, ou disciplina, que se propõe a explorar e integrar distintas áreas do conhecimento numa prática projetual" (PEREIRA NETO; SANTOS; VANDRESEN, 2017, p. 6).

\title{
3 DESIGN DE PRODUC̣ÃO AUDIOVISUAL
}

De acordo com Machado (2011), partindo dos elementos fundamentais que constituem a forma - ponto, linha e plano - foi proposta uma espécie de gramática visual comum a todos esses formatos visuais: pintura, escultura, arquitetura, artesanato, fotografia, artes gráficas e desenho industrial.

\begin{abstract}
São eles uma série de elementos que, como na linguagem verbal, são usados para compor e compreender mensagens em diversos níveis de utilidade, desde as mais funcionais e cotidianas, até produtos de um pensamento estético mais elaborado, domínio de expressão artística. (MACHADO, 2011, p. 63).
\end{abstract}

Conforme a autora, essa gramática visual é um "corpo de dados" composto por partes, um conjunto de unidades de informações distintas que, quando combinadas, constituem um determinado significado.

Machado (2011) aborda também os estudos da Gestalt (psicologia da forma), do início do século XX, no âmbito do alfabetismo visual. Segundo a autora, a base teórica da Gestalt reside na crença de que a análise de todos os sistemas demanda que se reconheça que o sistema, como um todo, é constituído por partes que interagem entre si.

Essas partes podem ser isoladas e analisadas como inteiramente independentes, e, depois, reunidas no todo. Portanto, modificando-se qualquer unidade de um determinado sistema, modifica-se, obrigatoriamente, o todo. "O conteúdo é extremamente influenciado pela importância das partes constitutivas, como a cor, o tom, a textura, a dimensão, a proporção e suas relações compositivas com o significado" (MACHADO, 2011, p. 68).

Assim, a comunicação visual aplica-se desde formas abstratas até as concretas, de imagens estáticas a imagens em movimento, de imagens simples a imagens complexas. 
A partir disso, entende-se a importância do aspecto visual no conceito de design. O design é uma prática abstrata e também concreta, ao passo que um projeto torna-se um produto, e é o aspecto visual - o mais superficial e, porém, o mais complexo - que manifesta todos os outros aspectos, sendo este o resultado concreto de todo o planejamento, e é a forma como o usuário percebe e interpreta o produto.

Semelhantemente, na produção audiovisual, o aspecto visual destacase em relação aos outros, considerando que "ao ver um filme, o objeto é a imagem" (MACHADO, 2011, p. 11). A essência do cinema enquanto técnica e arte é o conceito da imagem em movimento, "[...] imagem cinematográfica é constituída por um conjunto de representações visuais com um complexo sistema de significados, compondo um todo que constitui a linguagem visual do filme" (BUNGARTEN; NOJIMA, 2013, p. 2).

Assim, entende-se que tanto o audiovisual - não apenas no âmbito cinematográfico - quanto o design são áreas que trabalham com a narrativa visual. De acordo com Machado (2011), os fundamentos da linguagem de ambos têm a mesma origem:

\begin{abstract}
Vale lembrar que tanto o cinema quanto o design basearamse, em parte, nos mesmos princípios visuais já propostos pela pintura. Todas essas formas de representação trabalham a transposição do espaço real, que é onde vivemos, a um espaço plástico, que é o da superfície da imagem. (MACHADO, 2011, p. 71).
\end{abstract}

Isto posto, e devido à natureza transdisciplinar do design, tem-se a prática do Design de Produção Audiovisual, atualmente referida como intersecção entre as áreas de design e do audiovisual. Em análise histórica, tem-se que a primeira utilização do termo nesse sentido foi em 1939, quando o produtor David O. Selznick atribuiu o título a William Cameron Menzies por seu trabalho em ...E o Vento Levou (Gone with the Wind, Victor Fleming, 1939).

\begin{abstract}
Selznick reconheceu que Menzies fez muito mais que projetar os sets e a decoração; ele criou uma planta baixa para gravar o filme ao fazer o storyboard' de todo ele. Sua visualização detalhada de ...E o Vento Levou incorporou cor e estilo, estruturou cada plano, e englobava enquadramento, composição, e movimentos de câmera para cada cena do filme épico. (LOBRUTTO, 2002, p. 2, tradução nossa).
\end{abstract}

1 "O storyboard é a "colocação de imagens" do argumento, sob a forma de quadrinhos ilustrados" (JACQUINOT; SAINT-VINCENT; SAINT-VINCENT, 2006, p. 9). 
A contribuição de Menzies, nesse sentido, foi a expansão da função de Direção de Arte para além da criação de cenários e objetos, à medida que se incluiu a responsabilidade de planejar a visualidade do filme em sua inteireza.

Assim, as práticas de design e do audiovisual se fundem nessa função que faz uso da natureza projetual, do planejamento estratégico e das noções e saberes do design na atividade audiovisual.

LoBrutto (2002) define o Design de Produção Audiovisual como a arte e ofício visual da narrativa audiovisual. Segundo o autor, a função do designer de produção é de interpretar o roteiro e a visão do diretor para o filme, conceber uma lógica visual, uma metáfora, um conceito visual geral, partindo do abstrato à aplicação concreta: traduzir esses conceitos para ambientes físicos, transformando os temas da história, personagens e narrativa em imagens que envolvam arquitetura, decoração, espaço físico, tonalidade e textura.

Todos esses elementos pensados em conjunto irão suportar e contribuir para a coerência narrativa do filme como um todo. Sendo assim, e de acordo com o autor, o Design de Produção funciona na concepção visual a serviço da narrativa, no papel de comunicar, representar e criar experiência estética.

Entende-se que o designer de produção audiovisual faz o planejamento da concepção global da visualidade de um produto audiovisual, definindo o estilo e conceito visual através de cada elemento imagético, na definição de paleta de cor, pesquisa e concepção de arquitetura e época, cenários, produção de objetos, o figurino, a maquiagem, os efeitos especiais, no planejamento da montagem, das composições de quadro, enquadramentos e movimentos de câmera: na pré-produção, produção e pós-produção. Todos esses elementos dão suporte e contribuem para a coerência narrativa de um produto audiovisual como um todo.

Assim, é possível observar que os elementos fundamentais da imagem da teoria do design, explicitados anteriormente através das palavras de Machado (2011), são empregados no contexto do audiovisual com o propósito claro e sistemático de comunicar, imbuir significado e representar experiência estética.

De acordo com Bungarten e Nojima (2011), Luiz Antônio Coelho corrobora que, no futuro, o production designer brasileiro poderá sair dos cursos de graduação em Design, devido à formação global do designer que pode ampliar a formulação de conceitos e significados relacionados à imagem cinematográfica ${ }^{2}$. 
Fica evidente que as práticas projetuais, técnicas e saberes do design são unificados à prática audiovisual no Design de Produção Audiovisual, em um processo de cooperação extrema, transdisciplinar. Design de Produção Audiovisual consiste, portanto, na aplicação das práticas projetuais, técnicas e saberes do design junto à criação audiovisual, no intuito de obter um planejamento estratégico, objetivo e sistemático da imagem.

Ainda sobre a transdisciplinaridade, LoBrutto (2002) elucida que o designer de produção lidera o departamento de arte, e gerencia um time criativo que inclui diretores de arte, decoradores de set, pintores, carpinteiros, e outros especialistas. Além disso, afirma que "O estilo visual global de um filme vem da trindade composta pelo diretor, diretor de fotografia e do designer de produção" (LOBRUTTO, 2002, p. 6, tradução nossa), como representado na Figura 1 abaixo.

Figura 1 - representação da trindade criativa na produção audiovisual.

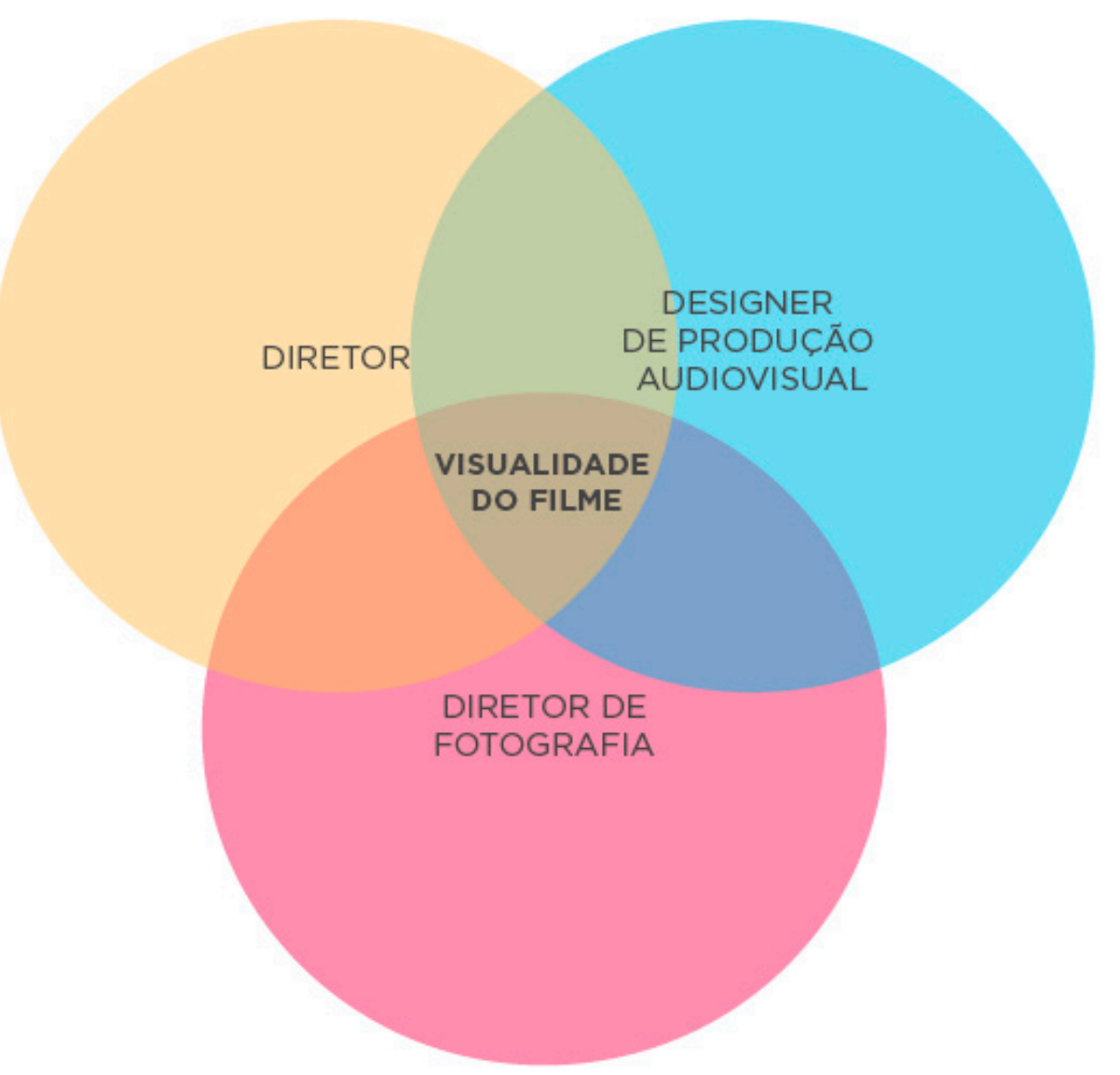

Fonte: elaborado pelo autor.

Bungarten e Nojima (2011, p. 2) corroboram que o desenho visual de um filme é resultado de uma obra coletiva, "[...] a fim de constituir um corpo coeso de significação através da representação imagética".

Assim, consiste em uma prática que unifica disciplinas, de maneira transdisciplinar, em um conjunto coerente, visando obter soluções criativas mais sofisticadas. Portanto, vai além da simples interação. 
Também é característico do Design de Produção Audiovisual, segundo LoBrutto (2002), que seja feito um planejamento da visualidade minuciosamente, uma vez que os detalhes enriquecem o filme ao torna-lo complexo e, assim, autêntico e verossímil.

Assim, a complexidade é inerente ao processo criativo no Design de Produção Audiovisual. É necessário conceber a visualidade de todos os aspectos do universo ficcional objetivando interpretar elementos históricos, psicológicos, emocionais e de atmosfera da história. Designers de produção audiovisual planejam cada cena "[...] do microscópico ao macroscópico detalhe" (LOBRUTTO, 2002, p. 1, tradução nossa).

\section{NARRATIVA TRANSMÍDIA}

O pesquisador Henry Jenkins (2009) sinaliza o surgimento do conceito de narrativa transmídia - uma nova sensibilidade que faz exigências aos consumidores e depende da participação ativa de comunidades de conhecimento.

A narrativa transmídia é a arte de criação de um universo. Para viver uma experiência plena num universo ficcional, os consumidores devem assumir o papel de caçadores e coletores, perseguindo pedaços da história pelos diferentes canais, comparando suas observações com as de outros fãs, em grupos de discussão on-line, e colaborando para assegurar que todos os que investiram tempo e energia tenham uma experiência de entretenimento mais rica. (JENKINS, 2009, p. 49).

Em uma narrativa transmídia, a história desenrola-se através de múltiplas plataformas de mídia, onde cada novo texto contribui de forma distinta e valiosa para o todo. Jenkins (2009) aponta que em sua forma ideal cada meio faz o que faz de melhor, sendo uma história introduzida em um filme, expandida pela televisão e quadrinhos, seu universo explorado através de jogos ou em parques de diversão.

Assim, cada plataforma contribui de uma forma para exploração do universo como um todo. Todas as partes devem ser integradas e consistentes e, para que isso ocorra, é melhor que as franquias sejam controladas por um único visionário ou unidade de criação. Jenkins (2009) explicita a necessidade de colaboração entre as unidades, em vez da competição.

Para Jenkins (2009), a cocriação ou autoria cooperativa possibilita variadas abordagens do enredo em um mesmo universo. Cada autor - em 
uma plataforma específica - expande potenciais significados e conexões intertextuais da franquia, guiado pela visão de um único e principal criador ou unidade criativa.

Dessa forma, as várias mídias são coerentes entre si, e não se estabelece uma mídia principal ou mídias periféricas.

Uma narrativa transmídia consiste na criação de um universo tão amplo que não pode ser contido em uma única mídia, integrando múltiplos textos. Segundo Lévy (2010), é desafiador criar obras com profundidade suficiente para justificar um empreendimento em tão larga escala.

Inúmeras informações são disponibilizadas para que os consumidores as estudem, pratiquem e dominem, podendo compreender as conexões entre cada parte do todo. "A compreensão obtida por meio de diversas mídias sustenta uma profundidade de experiência que motiva mais o consumo" (JENKINS, 2009, p. 135).

"À medida que a arte da criação de universos avança, a direção de arte assume um papel mais central na concepção de franquias" (JENKINS, 2009, p. 163). Assim, o autor explicita a importância dos fatores visuais - além dos aspectos narrativos - para a compreensão das características complexas de um universo ficcional transmídia.

Dessa forma, quanto mais complexo o universo, mais próximo à realidade e, portanto, mais interessante, empolgante e envolvente para o consumidor. A transmídia é uma estrutura narrativa que cria complexidade ao expandir a extensão de possibilidades narrativas, em vez de seguir um único caminho com começo, meio e fim.

Percebe-se, assim, algumas correspondências entre os conceitos de Design de Produção Audiovisual e narrativa transmídia, maiormente a respeito de transdisciplinaridade, complexidade, e a importância da imagem no papel de criar experiências interessantes e envolventes. Essas correspondências serão exploradas no capítulo a seguir.

\section{REFLEXÕES SOBRE DESIGN, DESIGN DE PRODUC̣ÃO E NARRATIVA TRANSMÍDIA}

Pode-se observar que o design, o Design de Produção e a narrativa transmídia têm aspectos-chave em comum, e percebe-se com clareza que compreender a relação entre esses conceitos pode ser bastante proveitoso. 
No decorrer dos últimos anos surgem novas formas de expressão visual, engendradas pelas tecnologias digitais. Ao mesmo tempo novos ramos se desenvolvem nos domínios do Cinema e do Design. Diluem-se as fronteiras entre estas duas atividades, tanto nas formas tradicionais assim como nas novas, e estas não são mais claramente diferenciadas - as suas linguagens se misturam (BUNGARTEN; NOJIMA, 2013, p. 178).

Fica evidente que a relação entre o design e a prática audiovisual - que dá origem ao Design de Produção Audiovisual - vai além da interdisciplinaridade, mas trata-se de uma relação transdisciplinar.

Destacando a transdisciplinaridade que ocorre entre os campos do design e do audiovisual, e sendo o design um domínio de natureza transdisciplinar, destaca-se a coerência em compreender a relação entre conceitos de Design de Produção Audiovisual à particularidade de um projeto transmídia.

Como explicitado anteriormente, o design e a produção audiovisual trabalham a imagem no sentido da concepção visual no papel de comunicar, representar e criar experiência estética. Essa proximidade entre as áreas permite a inter-relação entre elas, favorecendo o uso dos princípios e técnicas do design na concepção dos aspectos visuais a favor da narrativa.

É inevitável fazer essa relação entre as práticas de forma que, oriundo da intersecção entre o design e a narrativa audiovisual, tem-se o Design de Produção Audiovisual.

Compreendendo o design de produção no cinema como projeto de construção de um conceito visual que conjuga aspectos objetivos e subjetivos, com fins comunicacionais e simbólicos, podemos considerar a hipótese de inserção desta área de atuação no escopo do Design. (BUNGARTEN; NOJIMA, 2011, p. 2).

O Design de Produção Audiovisual herda a característica transdisciplinar do design, uma vez que a colaboração entre setores de produção do audiovisual é uma das principais características da prática.

"O desenho visual do filme, atualmente chamado "design de produção", reúne uma série de criações individuais numa unidade integrada, a fim de constituir um corpo coeso de significação através da representação imagética. É, portanto, o resultado de uma obra coletiva" (BUNGARTEN; NOJIMA, 2011, p. 2). Um produto audiovisual é, então, um projeto de linguagem visual, concebido e realizado coletivamente. 
Se a transdisciplinaridade é tão clara na produção de um projeto audiovisual, certamente acentua-se no contexto da narrativa transmídia. Enquanto que no âmbito audiovisual é preciso integrar os vários membros de uma equipe transdisciplinar - diretor, designer de produção audiovisual, sonorização, produtores, entre outros - no âmbito transmídia é preciso integrar todos os membros transdisciplinares das equipes de filmes, jogos, animações, quadrinhos, entre outras múltiplas possibilidades, tendo cada uma delas suas variadas particularidades criativas.

Considerando a afinidade entre os princípios de ambas as práticas, entende-se queé coerente unificar os saberes do Design de Produção Audiovisual para conceber, integralmente, a visualidade de um projeto transmídia. O esquema apresentado por Hayes (2011) de um time multi-plataforma básico (Figura 2) elucida a forma como o aspecto visual deve ser transdisciplinar no projeto transmídia.

Figura 2 - representação de um time multi-plataforma básico.

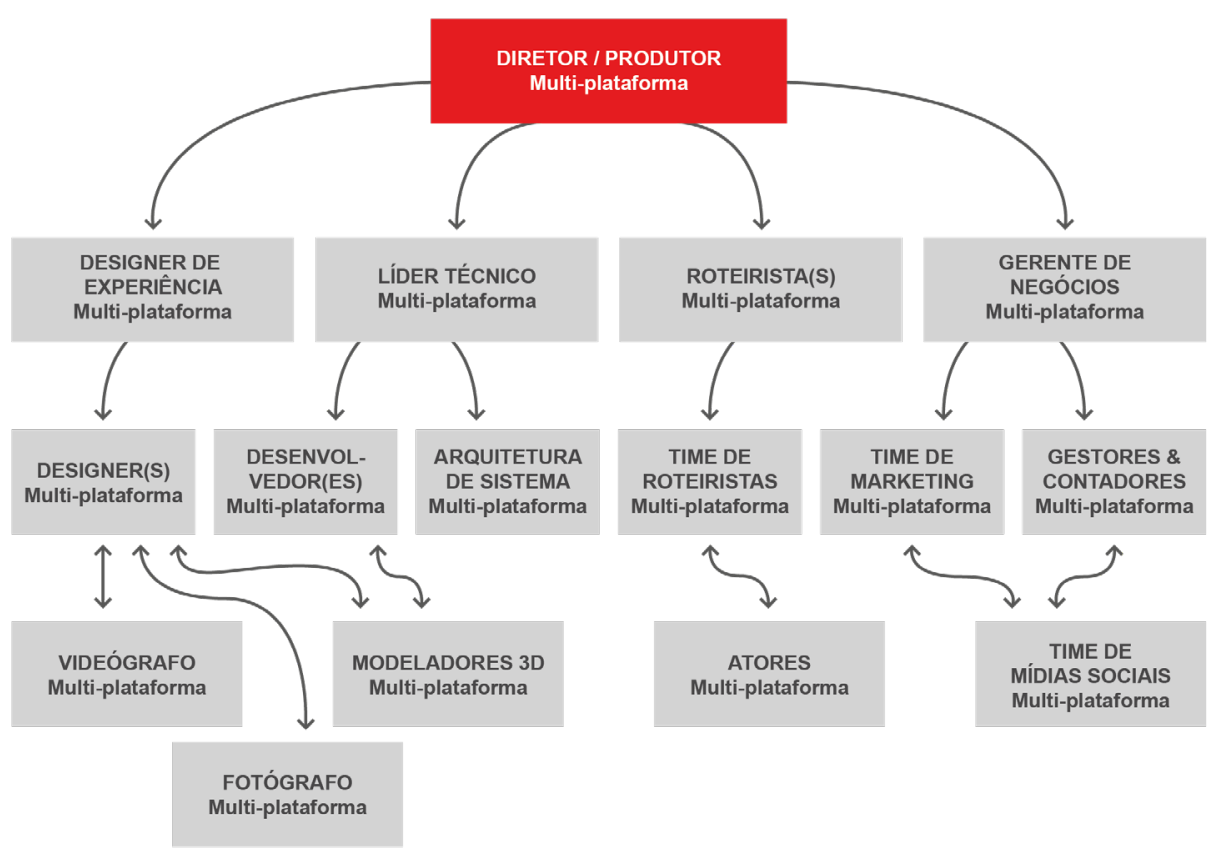

Fonte: Hayes (2011).

Outro aspecto em comum entre os princípios do Design de Produção Audiovisual e da narrativa transmídia é a importância dada ao ofício de criar um universo complexo, íntegro e autêntico.

LoBrutto (2002) observa que é preciso que o planejamento da visualidade de um audiovisual seja minucioso, pois os detalhes enriquecem o produto audiovisual ao torna-lo complexo, autêntico e verossímil. Assim, é necessário conceber a visualidade de todos os aspectos físicos do universo ficcional. 
Como visto anteriormente, uma narrativa transmídia demanda um universo tão complexo que não pode ser contido em uma única mídia. Um universo complexo precisa ter uma abordagem visual igualmente complexa, e "à medida que a arte da criação de universos avança, a direção de arte assume um papel mais central na concepção de franquias" (JENKINS, 2009, p. 163). Assim, Jenkins (2009) assume que os conceitos traduzidos através das escolhas visuais podem acrescentar inúmeras informações acerca das partes do universo ficcional, a fim de que o todo se torne mais convincente e compreensível.

Assim, sintetiza-se a relação observada entre o design, o Design de Produção Audiovisual e a narrativa transmídia através da Figura 3 abaixo.

Figura 3 - Representação das relações entre design, Design de Produção Audiovisual e narrativa transmídia

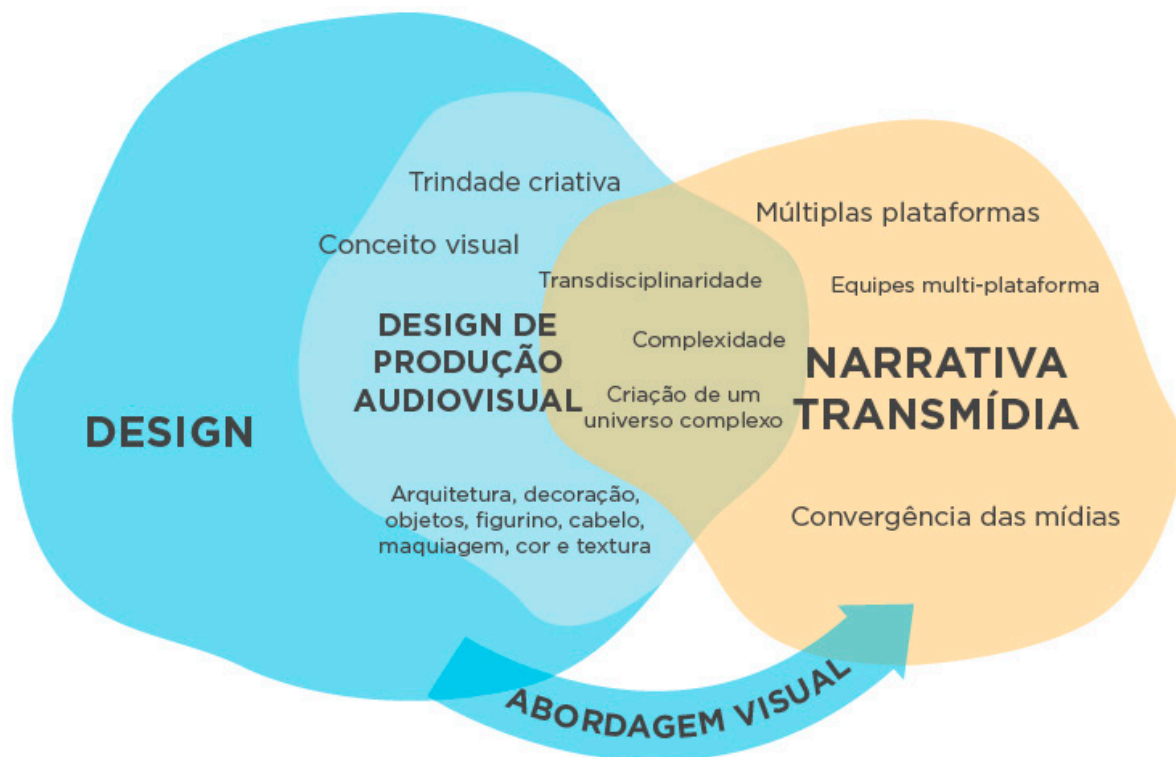

Fonte: elaborado pelo autor.

Entende-se que é possível e benéfico a aplicação dos conceitos em Design de Produção na narrativa transmídia, visando construir um universo íntegro, mesmo este envolvendo um grande número de disciplinas, devido às plataformas midiáticas diversas.

A existência de múltiplas plataformas dificulta a tarefa de construir um universo visualmente íntegro, considerando que cada forma de mídia tem sua linguagem muito própria. Nesse sentido, a natureza transdisciplinar do Design de Produção Audiovisual pode ser um aspecto positivo na função de unificar as partes através dos elementos visuais do universo da narrativa.

Como afirma Machado (2011, p. 69), "buscamos reforço visual do nosso conhecimento por muitas razões; a mais importante delas é o caráter direto da informação, a proximidade da experiência real". Considerando que o objetivo do designer de produção é fazer uso dos recursos visuais para aproximar a experiência do expectador do real e que, de acordo com Jenkins 
(2009), a narrativa transmídia visa fornecer uma experiência plena em um universo ficcional, depreende-se que é possível pensar a visualidade da narrativa transmídia sob o viés do pensamento estratégico e projetual do Design de Produção Audiovisual.

\section{CONSIDERAC̣ÕES FINAIS}

Mediante a revisão dos conceitos de design, Design de Produção Audiovisual e narrativa transmídia, este artigo teve o propósito de buscar e apresentar possíveis relações sobre esses temas. Baseando-se em determinados aspectos do design, como sua natureza transdisciplinar e os princípios da abordagem visual, foi possível traçar uma relação com o Design de Produção Audiovisual e, por fim, com a narrativa transmídia, sinalizando coerência entre os temas e a possibilidade de pensar os saberes e técnicas muito próprios do design no contexto do projeto transmídia.

Sugere-se, pois, que a pesquisa em Design de Produção na narrativa transmídia possa desempenhar papel valioso para compreender se e como é possível aplicar a prática do Design de Produção na narrativa transmídia, e também possa ajudar a entender melhor o papel do designer de produção em um projeto audiovisual e, até mesmo, descobrir novos conhecimentos que auxiliem na teoria e prática profissional do design.

Apesar da proximidade iminente entre áreas, verifica-se que o estado da arte da pesquisa no âmbito dos princípios e conceitos do Design de Produção aplicados à narrativa transmídia apresenta um cenário carente.

\section{AGRADECIMENTO}

Agradecemos a Fundação de Amparo à Pesquisa e Desenvolvimento Tecnológico do Maranhão - FAPEMA pelo apoio concedido ao autor para realizar a presente pesquisa.

\section{REFERÊNCIAS}

BOMFIM, Gustavo A. Fundamentos de uma teoria transdisciplinar do Design: morfologia dos objetos de uso e sistemas de comunicação. Estudos em Design, Rio de Janeiro, v. 5, n. 2, p. 27-41, 1997.

BUNGARTEN, Vera; NOJIMA, Vera. A imagem cinematográfica: convergência entre Design e Cinema. 2013. Tese (Doutorado em Design) - Departamento de Artes e Design, Pontifícia Universidade Católica do Rio de Janeiro, Rio de Janeiro.

BUNGARTEN, Vera; NOJIMA, Vera. Desenhando um filme: uma reflexão sobre as teorias do design. Estudos em Design, Rio de Janeiro, v. 19, n. 2, p. 1-13, 2011. 
KURZ, Lucas; et al.

CARDOSO, Rafael. Design para um mundo complexo. São Paulo: Cosac Naify, 2012.

COUTO, Rita; OLIVEIRA, Alfredo. Formas do design: por uma metodologia interdisciplinar. Rio de Janeiro: Ed. 2AB, 1999.

FAZENDA, Ivani. Integração e interdisciplinaridade no ensino brasileiro, efetividade ou ideologia. São Paulo: Loyola, 1979.

FONTOURA, Antônio. A interdisciplinaridade e o ensino do design. Projética: Revista Científica de Design, Londrina, v. 2, n. 2, p. 86-95, 2011.

GERHARDT, Tatiana; SILVEIRA, Denise. Métodos de pesquisa. Porto Alegre: Ed. da UFRGS, 2009.

HAYES, Gary. How to write a transmedia production bible: a template for multi-platform producers. Sydney: Screen Australia, 2011.

JACQUINOT, Rémi; SAINT-VINCENT, Olivier; SAINT-VINCENT, Raphaël. Guia prático do storyboard. Avanca: Ed. Cine-Clube de Avanca, 2006.

JENKINS, Henry. A cultura da convergência. 2. ed. São Paulo: Aleph, 2009.

LÉVY, Pierre. Cibercultura. 3. ed. São Paulo: Ed.34, 2010.

LOBRUTTO, Vincent. The filmmakers guide to production design. New York: Allworth Press, 2002.

MACHADO, Ludmila. Design e linguagem cinematográfica: narrativa visual e projeto. São Paulo: Bluncher, 2011.

MORIN, Edgar. Desafios da transdisciplinaridade e da complexidade. In: AUDY, Jorge Luis Nicolas; MOROSINI, Marília Costa. (Org.). Inovação e interdisciplinaridade na universidade. Porto Alegre: EDIPUCRS, 2007. p. 22-31.

MORIN, Edgar. Introdução ao pensamento complexo. 4. ed. Porto Alegre: Sulina, 2011.

PEREIRA NETO, David; SANTOS, Flavio dos; VANDRESEN, Monique. Criatividade e transdisciplinaridade no design. 2017. Disponível em: $<$ http://www.bocc.ubi.pt/pag/neto-santos-vendresen-2017-criatividadetransdisciplinaridade.pdf>. Acesso em: 4 jul. 2018.

POSSATTI, Giovana; VAN DER LINDEN, Júlio; SILVA, Régio. Reflexões sobre as relações entre design e complexidade. Estudos em Design, v. 23, n. 1, p. 118129, 2015.

VAN DER LINDEN, Júlio Carlos de Souza; LACERDA, André. P. Metodologia projetual em tempos de complexidade. In: MARTINS, R. F. F.; VAN DER LINDEN, Júlio Carlos de Souza. (Org.). Pelos caminhos do design: metodologia de projeto. Londrina: EDUEL, 2012. p. 83-149.

ZABALA, Anton. Enfoque globalizador e pensamento complexo. Porto Alegre: Artmed, 2002. 